\title{
Apresentação: Docência, Formação e Gestão
}

Lívia Freitas Fonseca Borges

Universidade de Brasília

É com satisfação que acolho o convite da revista Linhas Críticas para apresentar este volume que podemos categorizar como um dossiê sobre Formação de Professores. É igualmente significativo constatar que pesquisadores no campo educacional e professores mantêm o interesse em tornar a nossa profissão objeto vivo de reflexão e de proposição de novos caminhos e perspectivas para que aconteça um efetivo desenvolvimento profissional docente, na melhor definição que the confere o trabalho referencial de Imbernón (2005).

É bem provável que olals demais leitorela)s, assim como eu, identifiquem-se com os achados dos trabalhos empíricos e das reflexões traçadas a partir deles. Esta experiência torna-se significativa à medida que promovemos um profícuo diálogo entre olals diversolals pesquisadorelals do campo, de modo a solidificarmos, paulatinamente, uma literatura especializada a respeito da formação docente em nosso país. Uma literatura que nos ajude a pensar e propor políticas públicas mais efetivas no campo educacional, bem como encontrar caminhos mais plausíveis para a materialização destas políticas.

Os textos em seu conjunto procuraram abordar temáticas candentes para o campo da formação de professores no Brasil, que podem assim ser apontadas: locus da formação docente, itinerários formativos da formação inicial e da formação continuada em serviço; saberes docentes; especificidades do trabalho docente; relação teoria e prática na perspectiva de consolidação de uma práxis educativa; formação docente em nível superior, entre outras temáticas correlatas. É preciso problematizar as relações imanentes entre formação docente e qualidade do ensino e os textos ora apresentados, em diferentes proporções e abordagens, nos levam à necessidade desta problematização.

Em seu texto $A$ formação de professores na perspectiva crítico-emancipadora, Curado propõe a tecitura de um debate em torno da formação inicial de professores a partir da "[...] necessidade de se pensar a formação docente como esfera privilegiada de concretização de uma educação para a emancipação e autonomia do ser humano". As reflexões são apresentadas pela autora como derivações de pesquisas realizadas a respeito da temática. Ao pautar apropriadamente a pesquisa científica na formação do educador, a autora nos convida para uma análise mais aprofundada acerca daquilo que se convencionou chamar pesquisa em educação. 0 texto aponta para as fragilidades de ordem teórica e metodológica neste campo, as quais podem produzir, ao invés de um corpo teórico consolidado, uma miríade investigativa inócua que na verdade não nos leva 
ao desejável caminho da emancipação humana, e, portanto, da construção de uma educação emancipadora. 0 texto também nos possibilita uma compreensão crítica acerca do que a reflexão a respeito da prática pode produzir no campo estrito do senso comum.

Na contramão desta proposição, a autora nos chama a atenção para o fato da necessária superação da reflexão esvaziada que se faz no âmbito da prática educativa per se, quando não é capaz de gerar um conhecimento novo de expressão acadêmica e pedagógica de caráter transformador. A esse respeito, a autora avoca princípios decantados pela Associação Nacional pela Formação dos Profissionais da Educação - Anfope acerca da necessária consolidação de uma base teórica da formação docente que seja suficientemente capaz de produzir uma profícua interlocução no campo da prática, conduzindo o processo formativo e da prática profissional docente ao campo da práxis, na melhor acepção de Vazquez (1968), autor que compõe o diálogo teórico estabelecido pela autora.

No trabalho de Azevedo e Ramalho, as autoras revelam uma preocupação em desvelar um itinerário formativo docente no campo da formação continuada em serviço. 0 artigo, intitulado Formação Continuada de professores: os desafios da construção de propostas político-pedagógicas, deriva de pesquisa realizada nos anos de 2008 e 2009 na Universidade Estadual do Norte Fluminense. 0 objetivo da pesquisa foi analisar as implicações políticas e as práticas pedagógicas que permeiam o projeto de formação continuada de professores(as) para o Ensino Fundamental oferecido pela Equipe de Atualização Continuada (EAC/SEMC/RJ). A pesquisa aponta para a necessária interinstitucionalidade entre a universidade e o sistema público de ensino no que diz respeito à formação inicial e continuada de docentes que atuam ou atuarão futuramente nas escolas públicas da educação básica. A pesquisa tem o mérito de apontar a importância da centralidade da escola como instituição educativa preponderante na sociedade atual, razão pela qual, a nosso ver, não pode ser secundarizada nem excluída em processos de formação docente.

0 papel da universidade como locus da formação continuada de professores da educação básica também é lembrado no corpo do texto, com ênfase na produção de saberes específicos da profissão que são gerados no interior deste processo formativo. Contribuições igualmente importantes nos apresentam as respectivas autoras quando nos advertem que a repercussão positiva da formação continuada na prática pedagógica do professor não caminha por linearidade, mas que esta relação está atrelada a outros fatores, quando afirmam apropriadamente que: “A formação continuada é uma das dimensões importantes para a materialização de uma política para os profissionais da educação, e acreditamos que deve estar articulada à formação inicial e às boas condições de trabalho, salário e carreira".

0 trabalho empírico realizado por Azevedo e Ramalho clama por uma política pública de formação docente a ser fomentada pela Secretaria de Educação em conjunto com a universidade. Isto provoca a configuração de um processo de formação continuada em 
serviço estruturado em outras bases, diversas das costumeiramente ofertadas, da forma como se expressa no trecho seguinte: "A maioria dos cursos é ministrada no mesmo período em que os professores estão lecionando, e as escolas não podem liberá-los porque não estão preparadas para substituí-los nesses momentos de ausência". Essas ideias nos remetem à necessária reflexão a respeito do falseamento da incompatibilidade entre formação docente e trabalho pedagógico. Uma gestão educacional que se deseja consolidar em estruturas e princípios democráticos demanda uma política de formação inicial, continuada e em serviço que inequivocamente proverá todas as condições para que seu quadro docente tenha o processo formativo garantido dentro da jornada de trabalho.

Em Profissão docente: representações sociais de professoras da educação básica, Machado e Santos apresentam os resultados de pesquisa empírica realizada na rede municipal de ensino de Jaboatão dos Guararapes - PE, cujos dados foram captados por meio de entrevistas semiestruturadas desenvolvidas com vinte professoras de seis escolas que compõem a respectiva rede de ensino. A pesquisa revela um dado preocupante para a universidade como instituição formadora de professores da educação básica ao tratar da falta de eficiência desse processo formativo e sua baixa repercussão no campo da prática docente, o que pode se depreender da seguinte explanação: “As professoras concordam sobre a importância de se ter uma boa formação, porém reconhecem que nem sempre o conhecimento adquirido na academia supre as reais necessidades diárias".

A pesquisa como componente curricular indispensável à formação docente também é apropriadamente abordada por Ahlert em seu texto intitulado Educação e esperança na formação docente: diálogos entre a pedagogia e a teologia. 0 autor acredita que "0 diálogo sustentado na esperança possibilita refazer a reflexão, superar as contradições, evidenciar novas perguntas e acrescentar novas dimensões à formação docente inicial e continuada com o intuito de superar sua crise".

Partindo do pressuposto de que há uma crise instalada entre a educação e a docência, o autor argumenta que “Educação e profissão docente se debatem numa profunda crise neste início do século XXI. Da educação a humanidade espera a redenção de todos os males. Consequentemente, da profissão docente se espera a solução de todos os problemas que envolvem a complexa tarefa de educar as novas gerações, que cada vez mais nascem e crescem em situações e realidades marcadas, de um lado, por uma competição voraz, e, de outro, por uma vaziez de sentido".

Numa construção textual bastante objetiva, Ahlert nos convida a repensar as demandas sociais por repercussões imediatistas da formação docente na prática pedagógica: “0 professor ou professora, em sua formação inicial e continuada, precisa ter consciência de que o resultado do processo educativo é de longo prazo, ou seja, não é instantâneo, 
em tempo real, como se espera na atualidade". A necessária formação epistemológica bem consolidada, perfilada pela formação do pesquisador, também figura no texto do referido autor como temática importante no processo de formação docente inicial e continuada.

Em Universidade: espaço privilegiado para a formação de professores de educação física, Ventura desenvolve uma importante análise em torno da configuração epistemológica da Educação Física na sua relação entre as Ciências da Saúde e as Ciências Humanas e Sociais. 0 texto está estruturado a partir de correntes teóricas e históricas da Educação Física no Brasil a partir do diálogo com alguns teóricos da Educação e da Educação Física, revelando uma preocupação com o caráter crítico da formação docente no campo pesquisado. 0 autor apresenta uma pertinente crítica quanto aos efeitos da estrutura departamental da universidade, o que repercute na fragmentação da organização dos conhecimentos veiculados pelos currículos dos cursos. 0 autor discute a formação do profissional na universidade, enfatizando a pesquisa e problematizando a fragmentação do conhecimento que provém de estruturas departamentais e curriculares desarticuladas. Apropriadamente, reivindica o protagonismo de estudantes como centro orientador do processo pedagógico. Da mesma forma, posiciona a instituição escolar como locus propulsor da almejada educação democrática e destaca a importância da educação Física neste contexto.

Em geral, os textos são apresentados como resultados de pesquisas realizadas pelos respectivos autores e autoras, e sinalizam a continuidade do debate acadêmico acerca da temática em pauta. 0 debate profícuo em torno da formação docente e gestão não se esgota aqui e demanda a sua continuidade e aprofundamento; esta nos parece uma ideia que perpassa o conjunto das reflexões apresentadas pelos trabalhos que compõem o presente dossiê, da qual compartilhamos.

\section{Referências}

VAZQUEZ, A. S. Filosofia da práxis. Rio de Janeiro: Paz e Terra, 1968.

IMBERNÓN, F. Formação docente e profissional: formar-se para a mudança e a incerteza. São Paulo: Cortez, 2005.

Lívia Freitas Fonseca Borges possui doutorado em Sociologia e mestrado em Educação pela Universidade de Brasília. É professora adjunta da Faculdade de Educação da Universidade de Brasília. Tem experiência na área de Educação Básica, Educação Profissional e Educação Superior, atuando principalmente nos seguintes temas: currículo, formação docente, pedagogia e educação superior. E-mail: liviaborgeslafe.unb.br. 